\title{
Eficiência de Herbicidas Pré-Emergentes após Períodos DE SECA
}

\author{
Efficiency of Pre-Emergence Herbicides After Different Periods of Drought
}

MONQUERO, P.A. ${ }^{2}$, BINHA, D.P. ${ }^{3}$, SILVA, A.C. ${ }^{4}$, SILVA, P.V. ${ }^{5}$ e AMARAL, L.R. ${ }^{5}$

\begin{abstract}
RESUMO - Objetivou-se, com este trabalho, estudar a eficácia de herbicidas pré-emergentes após períodos de seca, em dois tipos de solo. Foram realizados dois ensaios simultâneos em casa de vegetação: no primeiro foram aplicados os herbicidas (trifloxysulfuron-sodium + ametryn $\left.-351+99 \mathrm{~g} \mathrm{ha}^{-1}\right)+\left(\right.$ diuron + hexazinone $\left.-1.097+27,77 \mathrm{~g} \mathrm{ha}^{-1}\right)$, trifloxysulfuronsodium + ametryn $-1.463+37 \mathrm{~g} \mathrm{ha}^{-1}$, diuron + hexazinone $-1.170+330 \mathrm{~g} \mathrm{ha}^{-1}$, imazapyr $200 \mathrm{~g} \mathrm{ha}^{-1}$ e imazapic - 122,5 $\mathrm{g} \mathrm{ha}^{-1}$, em vasos com amostras de Latossolo Vermelho distroférrico (textura argilosa); e, no segundo, as doses foram ajustadas em função dos teores de matéria orgânica e argila do solo e aplicadas em vasos com amostras de Latossolo Vermelho distrófico (textura média). Em cada ensaio, foram utilizados Cucumis sativus e Sorghum bicolor como espécies bioindicadoras e seis periodos de seca após as aplicações dos herbicidas $(0,10,20,40,60$ e 90 dias), com quatro repetições. Os sintomas de intoxicação foram observados aos 7, 14 e 21 dias após semeadura dos bioindicadores. Os herbicidas apresentaram maior estabilidade, ou seja, maior efeito tóxico sobre os bioindicadores ao longo do tempo, no solo com maior teor de argila e matéria orgânica; o isoxaflutole e as misturas (trifloxysulfuron-sodium + ametryn) + (diuron + hexazinone) e diuron + hexazinone demonstraram maior efeito residual em ambos os solos, afetando o desenvolvimento dos bioindicadores em $100 \%$.
\end{abstract}

Palavras-chave: bioindicador, condições climáticas, persistência.

\begin{abstract}
This work aimed to study the effectiveness of pre-emerging herbicides after drought periods in two soil types. Two simultaneous experiments were carried out under greenhouse conditions: in the first, the herbicides (trifloxysulfuron-sodium + ametryn $-351+99 \mathrm{~g} \mathrm{ha} \mathrm{h}^{-1}$ ) + (diuron + hexazinone $-1097+27,77 \mathrm{~g} \mathrm{ha}^{-1}$ ), trifloxysulfuron-sodium + ametryn - $1463+37 \mathrm{~g} \mathrm{ha}^{-1}$, diuron + hexazinone $-1170+330 \mathrm{~g} \mathrm{ha}^{-1}$, imazapyr-200 $\mathrm{g} \mathrm{ha}^{-1}$ and imazapic-122, $5 \mathrm{~g} \mathrm{ha}^{-1}$ were applied in vases containing samples of Dystroferric Red Latosol (clay texture); in the second, the doses were adjusted in function of the organic matter and clay level of the soil and applied in vases with samples of Distrophic Red Latosol (medium texture). In each experiment, the species Cucumis sativus and Sorghum bicolor were used as bioindicators and 6 drought periods after herbicide applications (0,10,20,40,60 and 90 days), with four replicates. Intoxication symptoms were observed on the 7, 14 and 21 days after the bio indicators were sown. The herbicides presented greater stability, i.e. greater toxic effects on the bioindicators along the time on soil with higher clay level and organic matter; isoxaflutole and the mixtures (trifloxysulfuron-sodium + ametryn) + (diuron + hexazinone), and diuron + hexazinone showed greater residual effect in both soils affecting the bioindicators $100 \%$.
\end{abstract}

Keywords: bioindicator, climatic conditions, persistence.

Recebido para publicação em 2.8.2007 e na forma revisada em 27.2.2008

2 Professora adjunta do Centro de Ciências Agrárias/UFSCar, Rodovia Anhanguera, km 174, 13600-970, Araras-SP, <pamonque@cca.ufscar.br>; ${ }^{3}$ Aluno de graduação do Centro de Ciências Agrárias/UFSCar - bolsista CNPq; ${ }^{4}$ Pesquisadora científica do Pólo Regional da Alta Sorocabana, Rodovia Raposo Tavares, km 561 Caixa Postal 298, 19015-970 Presidente Prudente-SP; 5 Alunos de graduação do Centro de Ciências Agrárias/UFSCar. 


\section{INTRODUÇÃO}

O controle químico de plantas daninhas em áreas de cana-de-açúcar é uma prática bastante difundida em todo o País (Freitas et al., 2004). Entre as diversas opções de herbicidas registrados para a cultura encontram-se os herbicidas inibidores da acetolactato sintase (ALS), como o imazapic, imazapyr e trifloxysulfuronsodium. Também são utilizados herbicidas inibidores do fotossistema II, como ametryn e diuron, assim como os inibidores da sintese de carotenóides, como isoxaflutole e clomazone. Existem também algumas misturas, como, por exemplo, trifloxysulfuron-sodium + ametryn, diuron + hexazinone e clomazone + ametryn (Rodrigues \& Almeida, 2005). A maioria desses herbicidas apresenta ação em pré e pós-emergência inicial, sendo recomendados para controle de gramineas e folhas largas e perenes de difícil controle (Procópio et al., 2004).

A utilização de herbicidas pré-emergentes com efeito residual prolongado é um dos fatores que determinam grande eficiência no controle de plantas daninhas durante o período crítico de competição. Com essa alternativa, torna-se possivel a execução de planos para controle efetivo de plantas infestantes na lavoura (Miller et al., 1995).

Assim, o conhecimento dos fatores que influenciam a atividade e estabilidade desses herbicidas no solo é fundamental, uma vez que determina o sucesso ou o fracasso desses produtos no controle das plantas daninhas, bem como sua persistência em diferentes condições ambientais (Anderson, 1983).

A persistência varia de acordo com a estrutura química da molécula, o tipo de solo e as condições climáticas, como a umidade do solo, que afetam por sua vez a adsorção, lixiviação e decomposição microbiana e química (Silva et al., 1999). No Estado de São Paulo, a canade-açúcar é colhida durante o inverno (junho a agosto), época de pouca ocorrência de chuvas. No entanto, muitos produtores, devido às questões de planejamento e operações agrícolas, optam por utilizar o controle químico mesmo durante o período seco (Azânia et al., 2006).

As características que contribuem para manutenção da eficiência dos herbicidas no solo por períodos de seca são: baixa volatilidade, não-fotodegradáveis, alta solubilidade, baixa adsorção aos colóides do solo e degradação principalmente via microbiana, já que nesta condição de solos secos muitos microrganismos passam ao estádio de repouso e tornamse inativos (Guimarães, 1987). Assim, herbicidas com propriedades químicas diferentes devem apresentar comportamentos distintos quando aplicados em condições de seca.

A atividade do isoxaflutole, por exemplo, depende da conversão em metabólito diquetonitrila, de acordo com a disponibilidade de água no solo (Mitra et al., 2000). Aplicações desse herbicida podem ser feitas durante todo o período mais seco do ano. Assim que se registra a ocorrência de chuvas, a conversão passa a acontecer simultaneamente à emergência das plantas daninhas, o que prolonga sua atividade residual no campo. Esse fato é particularmente interessante para as áreas de corte de cana que se concentram entre os meses de maio e agosto, em que muitos herbicidas não são efetivos, devido à baixa disponibilidade de água no solo (Marchiori Jr. et al., 2005).

O tipo de solo também exerce papel importante no efeito residual dos herbicidas aplicados em pré-emergência. O isoxaflutole, por exemplo, também usado em áreas cultivadas com cana-de-açúcar, apresentou maior período residual em solo de textura argilosa, independentemente da dose, devido às diferenças de carbono orgânico e argila entre solos arenosos e argilosos (Marchiori Jr. et al., 2005).

Tendo em vista a importância que a aplicação de herbicidas vem assumindo em épocas secas e considerando a carência de informações, sobretudo em condições tropicais, objetivou-se com o presente trabalho estudar o efeito residual dos herbicidas formulados (trifloxysulfuron-sodium + ametryn) + (diuron + hexazinone), trifloxysulfuron-sodium + ametryn, imazapyr, imazapic, diuron + hexazinone, clomazone + ametryn e isoxaflutole, submetidos a diferentes periodos de seca, em dois solos de texturas diferentes.

\section{MATERIAL E MÉTODOS}

Foram instalados dois experimentos em casa de vegetação, na Universidade Federal de São Carlos, em 2006. As amostras dos solos 
utilizadas nos ensaios foram provenientes do horizonte subsuperficial (5 a $20 \mathrm{~cm}$ ) de dois locais do municipio de Araras. As características químicas e físicas das amostras dos solos são apresentadas na Tabela 1. As amostras dos solos foram peneiradas e secas ao ar, sendo posteriormente acondicionadas em vasos plásticos com capacidade de $5 \mathrm{~L}$, sendo estes as unidades experimentais.
Os herbicidas clomazone + ametryn $-1.500+$ $1.000 \mathrm{~g} \mathrm{ha}^{-1} \mathrm{e}$ isoxaflutole $-60 \mathrm{~g} \mathrm{ha}^{-1}$ também foram avaliados nos seis períodos de seca. As plantas bioindicadores foram as mesmas do experimento 1 . As doses menores de alguns herbicidas neste ensaio foram devido à recomendação para este tipo de solo. O delineamento experimental utilizado em ambos os ensaios foi o inteiramente casualizado, com quatro

Tabela 1 - Características químicas e físicas de amostras dos solos utilizados nos experimentos

\begin{tabular}{|c|c|c|c|c|c|c|c|c|c|c|c|c|c|}
\hline \multirow{2}{*}{ Amostra } & \multirow{2}{*}{$\underset{\mathrm{pH}}{\mathrm{pHCl}}$} & \multirow{2}{*}{$\begin{array}{c}\mathrm{MO} \\
\mathrm{g} \mathrm{dm}^{-3}\end{array}$} & \multirow{2}{*}{$\begin{array}{c}\mathrm{P} \\
\mathrm{mg} \mathrm{dm^{-3 }}\end{array}$} & $\mathrm{K}$ & $\mathrm{Ca}$ & $\mathrm{Mg}$ & $\mathrm{Al}$ & \multirow{2}{*}{ SB } & \multirow{2}{*}{ CTC } & \multirow{2}{*}{$\begin{array}{l}\text { V\% } \\
\%\end{array}$} & Argila & Silte & Areia \\
\hline & & & & \multicolumn{4}{|c|}{ - $\mathrm{mmol}_{\mathrm{c}} \mathrm{dm}^{-3}$} & & & & \multicolumn{3}{|c|}{ - } \\
\hline $\mathrm{LV}^{\underline{1}}$ & 5,3 & 22 & 12 & 2,3 & 28 & 11 & 0 & 41,3 & 65,3 & 63 & 320 & 170 & 510 \\
\hline $\mathrm{LV}^{2 / /}$ & 4,7 & 36 & 7 & 2,9 & 25 & 13 & 0 & 40,9 & 68,9 & 59 & 530 & 320 & 150 \\
\hline
\end{tabular}

1- Latossolo Vermelho distrófico; 2- Latossolo Vermelho distroférrico.

No experimento 1 foi utilizado Latossolo Vermelho distroférrico (Embrapa, 1999), sendo avaliada a eficácia dos herbicidas formulados (trifloxysulfuron-sodium + ametryn - 351 + $\left.99 \mathrm{~g} \mathrm{ha}^{-1}\right)+($ diuron + hexazinone $-1.097+$ $27,77 \mathrm{~g} \mathrm{ha}^{-1}$ ), trifloxysulfuron-sodium + ametryn $-1.463+37 \mathrm{~g} \mathrm{ha}^{-1}$, diuron + hexazinone -1.170 + $330 \mathrm{~g} \mathrm{ha}^{-1}$, imazapyr $-200 \mathrm{~g} \mathrm{ha}^{-1}$ e imazapic $-122,5 \mathrm{~g} \mathrm{ha}^{-1}$, nas respectivas doses. O solo foi submetido a seis períodos de seca $(0,10,20$, 40, 60 e 90 dias após aplicação dos herbicidas - DAA), no esquema fatorial $5 \times 6$ (herbicidas $x$ periodos de seca), utilizando Cucumis sativus como planta bioindicadora. Os herbicidas clomazone + ametryn $-1.500+1.000 \mathrm{~g} \mathrm{ha}^{-1} \mathrm{e}$ isoxaflutole $-67,5 \mathrm{~g} \mathrm{ha}^{-1}$ também foram avaliados nos seis períodos de seca, no esquema fatorial 2 x 6 (herbicidas e períodos de seca), utilizando Sorghum bicolor como planta bioindicadora. Os herbicidas clomazone + ametryn e isoxaflutole foram analisados separadamente, pelo fato de as plantas-teste serem distintas $(S$. bicolor $\mathrm{e}$ C. sativus).

No experimento 2 foi utilizado Latossolo Vermelho distrófico (EMBRAPA, 1999), sendo avaliada a eficácia dos herbicidas formulados (trifloxysulfuron-sodium + ametryn - 351+ $\left.99 \mathrm{~g} \mathrm{ha}^{-1}\right)+($ diuron + hexazinone $-1.097+$ 27,77 $\mathrm{g} \mathrm{ha}^{-1}$ ), trifloxysulfuron-sodium + ametryn $-1.463+37 \mathrm{~g} \mathrm{ha}^{-1}$, diuron + hexazinone $936+264 \mathrm{~g} \mathrm{ha}^{-1}$, imazapyr $-125 \mathrm{~g} \mathrm{ha}^{-1} \mathrm{e}$ imazapic - $105 \mathrm{~g} \mathrm{ha}^{-1}$, nas doses respectivas, nos mesmos períodos de seca do experimento 1 . repetições. Foram monitoradas as temperaturas médias referentes ao período de condução do ensaio (Tabela 2).

Tabela 2 - Dados climatológicos da região de Araras, durante a condução do experimento

\begin{tabular}{|c|c|c|c|}
\hline \multirow{2}{*}{$\begin{array}{c}\text { Semanas após } \\
\text { aplicação dos } \\
\text { herbicidas }\end{array}$} & \multicolumn{3}{|c|}{ Temperatura $\left({ }^{\circ} \mathrm{C}\right)$} \\
\cline { 2 - 4 } & $\mathrm{T}_{\text {máx }}$ & $\mathrm{T}_{\text {mín }}$ & $\mathrm{T}_{\text {méd }}$ \\
\hline $1^{\underline{\mathrm{a}}}$ & 31,4 & 16,2 & 25,7 \\
\hline $2^{\underline{\mathrm{a}}}$ & 30,6 & 15,6 & 24,5 \\
\hline $3^{\underline{\mathrm{a}}}$ & 33,2 & 18,0 & 26,9 \\
\hline $4^{\underline{\mathrm{a}}}$ & 30,6 & 18,4 & 24,0 \\
\hline $5^{\mathrm{a}}$ & 31,0 & 18,8 & 22,2 \\
\hline $6^{\mathrm{a}}$ & 30,4 & 19,6 & 25,0 \\
\hline $7^{\underline{\mathrm{a}}}$ & 32,8 & 18,2 & 24,8 \\
\hline $8^{\mathrm{a}}$ & 30,0 & 18,2 & 24,4 \\
\hline $9^{\underline{\mathrm{a}}}$ & 31,4 & 17,4 & 22,8 \\
\hline $10^{\mathrm{a}}$ & 33,4 & 16,8 & 24,4 \\
\hline $11^{\underline{\mathrm{a}}}$ & 31,6 & 16,0 & 24,6 \\
\hline $12^{\underline{\mathrm{a}}}$ & 33,8 & 16,0 & 24,8 \\
\hline
\end{tabular}

Os herbicidas foram aplicados em pré-emergência sobre solo seco, utilizando-se um pulverizador costal de pressão constante, pressurizado por $\mathrm{CO}_{2}$, com quatro pontas do tipo leque XR 110.02, espaçadas de 0,5 m e com pressão de $2,0 \mathrm{kgf} \mathrm{cm}^{-2}$, o que proporcionou a aplicação de $200 \mathrm{~L} \mathrm{ha}^{-1}$ de calda herbicida. 
Os períodos de seca referem-se ao tempo, a partir da aplicação do produto, em que os vasos foram mantidos sem irrigação e semeadura do bioindicador. Transcorridos os períodos de seca previamente estabelecidos, foi realizada a semeadura dos bioindicadores (três sementes por vaso - quantidade estabelecida após teste de germinação) e, imediatamente após, aplicada lâmina de $20 \mathrm{~mm}$ de água, considerada suficiente para ativar os produtos que são aplicados no solo em áreas de plantio direto (Velini et al., 2002).

Após aplicação da lâmina de água, os vasos foram mantidos com irrigação diária até o encerramento das avaliações, aos 21 dias após a semeadura (DAS) do bioindicador. O controle foi avaliado visualmente aos 7, 14 e 21 DAS por meio de escala percentual de notas, em que zero corresponde a nenhuma injúria na planta e 100, à morte das plantas, seguindo a metodologia proposta por ALAM (1974).

Os dados de porcentagem de controle das culturas bioindicadoras foram submetidos à análise de variância e regressão. Os modelos foram escolhidos considerando-se a significância dos coeficientes de regressão, utilizando-se o teste t a $5 \%$ de probabilidade, o coeficiente de determinação e o significado biológico.

\section{RESULTADOS E DISCUSSÃO}

\section{Latossolo Vermelho distroférrico (textura argilosa)}

Aos 7 dias após a semeadura (DAS), a mistura diuron + hexazinone apresentou efeito residual no solo, culminando em maior intoxicação das plantas do bioindicador $C$. sativus. Entretanto, todos os herbicidas apresentaram atividade residual menor à medida que se prolongaram os períodos em que os solos ficaram expostos à condição de seca (Figura 1).

As médias de controle aos 14 e 21 DAS do bioindicador para (trifloxysulfuron-sodium + ametryn) + (diuron + hexazinone) e diuron + hexazinone foram iguais ou superiores a $90 \%$ em todos os períodos de seca avaliados (Figura 1). O resultado favorável neste tipo de solo devese provavelmente ao fato de esses herbicidas serem adsorvidos a matéria orgânica, minerais de argila e óxidos metálicos do solo.
Enquanto adsorvidos, ficam menos expostos aos processos de degradação e transporte, o que pode prolongar o efeito residual no solo (Langenbach, 2006). O processo de adsorção retarda ou, em alguns casos, até mesmo impede o movimento e a ação de herbicidas no perfil do solo. Entretanto, depois de sorvida, uma fração das moléculas pode retornar à solução do solo e exercer a atividade herbicida, sendo esse processo conhecido como dessorção (Bouchard et al., 1989).

A mistura trifloxysulfuron-sodium + ametryn manteve atividade residual estável até 40 dias de seca depois da aplicação; após esse período, houve redução gradativa na sua atividade residual. $\mathrm{O}$ imazapic apresentou atividade residual, quando submetido a 90 dias de seca, capaz de causar intoxicação da ordem de $80 \%$ (Figura 1) em avaliação realizada aos 21 DAS do bioindicador. Esse comportamento está associado à degradação desse produto no solo, que é essencialmente microbiana, sendo favorecida, portanto, por condições úmidas e quentes (Renner et al., 1998).

O imazapyr submetido a condições de solo seco por período superior a 60 dias teve seu efeito herbicida reduzido no controle do bioindicador (Figura 1). No campo, a persistência biológica do imazapyr é dependente da dose e das condições ambientais, com degradação mais rápida em climas quentes e úmidos. Estudos de dissipação do imazapyr no solo em condições de umidade normais mostram que este herbicida apresenta resíduos declinando para niveis insignificantes ou não-detectáveis dentro de três a sete meses após aplicação, sem alcançar profundidade significativa e com pouco movimento lateral no solo (Rodrigues \& Almeida, 2005). Em trabalho posterior, Souza et al. (2006) observaram que a exsudação radicular do imazapyr por diferentes clones de Eucalyptus grandis proporcionou a presença deste herbicida até $30 \mathrm{~cm}$ de profundidade no solo.

O herbicida clomazone + ametryn apresentou efeito residual menor ao longo do tempo, diferentemente do que ocorreu com isoxaflutole, que foi indiferente em relação ao periodo em que é exposto ao solo seco, apresentandose eficiente no controle de $S$. bicolor, independentemente do período analisado (Figura 2). Os resultados do isoxaflutole confirmam o exposto por Marchiori Jr. et al. (2005): que a atividade 

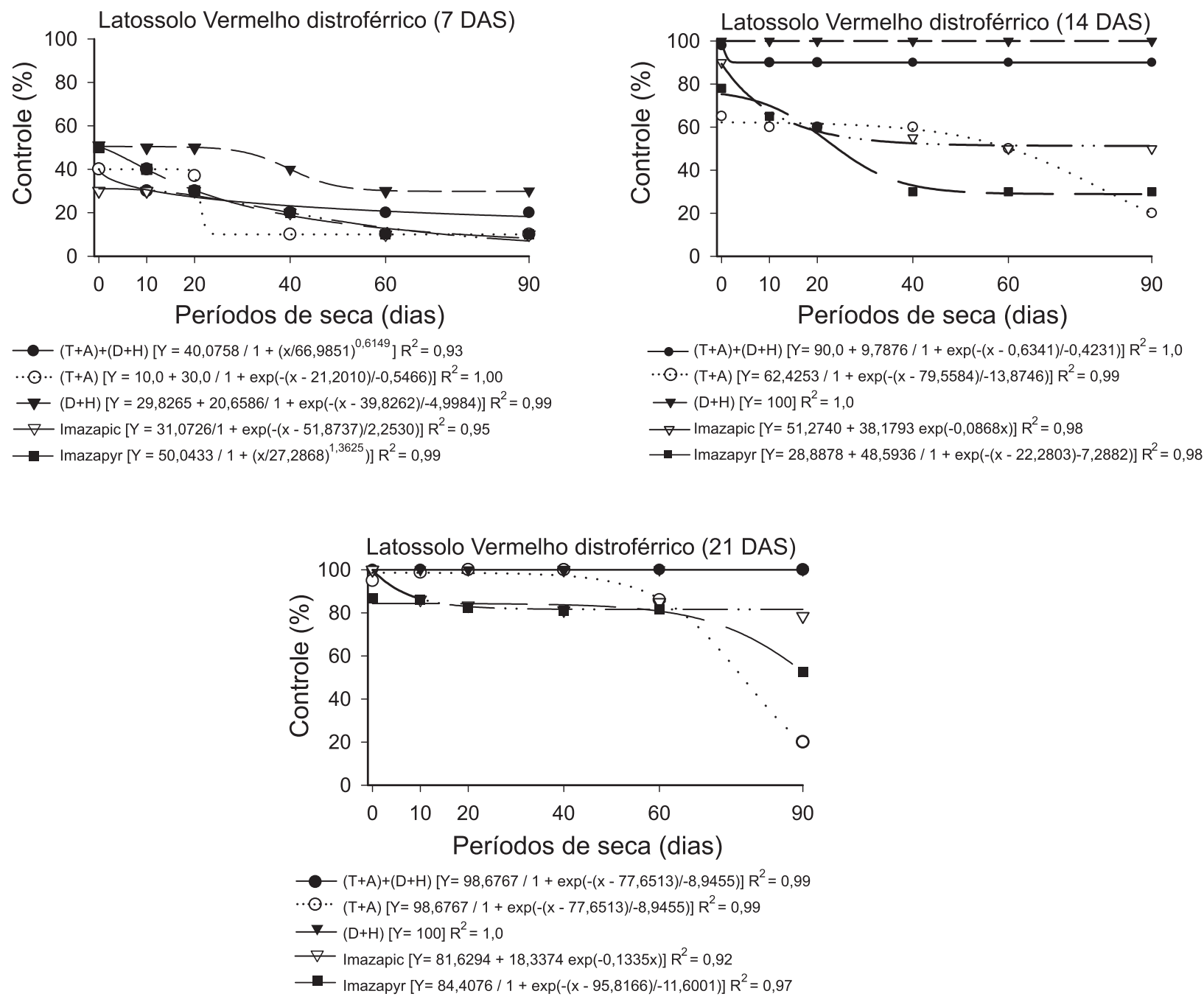

Figura 1 - Efeito residual dos herbicidas trifloxysulfuron-sodium $(\mathrm{T})+\operatorname{ametryn}(\mathrm{A})+$ diuron $(\mathrm{D})+$ hexazinone $(\mathrm{H})$, trifloxysulfuronsodium + ametryn, diuron + hexazinone, imazapic e imazapyr sobre C. sativus aos 7, 14 e 21 DAS, aplicados em Latossolo Vermelho distroférrico.

deste herbicida depende da conversão em metabólito diquetonitrila, o que por sua vez depende de disponibilidade de água no solo. Desse modo, aplicações desse herbicida podem ser feitas durante todo o período mais seco do ano. Assim que se registra a ocorrência de chuvas, a conversão passa a acontecer simultaneamente à emergência das plantas daninhas, o que prolonga sua atividade residual no campo.

\section{Latossolo Vermelho distrófico (textura média)}

Aos 7 DAS detectou-se maior intoxicação de $C$. sativus às misturas (trifloxysulfuronsodium + ametryn) + (diuron + hexazinone) e diuron + hexazinone em todos os períodos em que o solo foi mantido seco. Entretanto, com o aumento do período seco, o efeito dos herbicidas sobre $C$. sativus foi menor (Figura 3 ).

Aos 14 e 21 DAS, a mistura (trifloxysulfuron-sodium + ametryn) + (diuron + hexazinone) e diuron + hexazinone afetaram o desenvolvimento do bioindicador em $100 \%$, mostrandose estáveis ao longo do tempo (Figura 3). A mistura trifloxysulfuron-sodium + ametryn aplicada isoladamente apresentou baixo efeito sobre o bioindicador, o qual foi reduzindo à medida que se prolongou o período de seca. Os herbicidas imazapic e imazapyr também mostraram menor eficácia com o incremento dos períodos de 

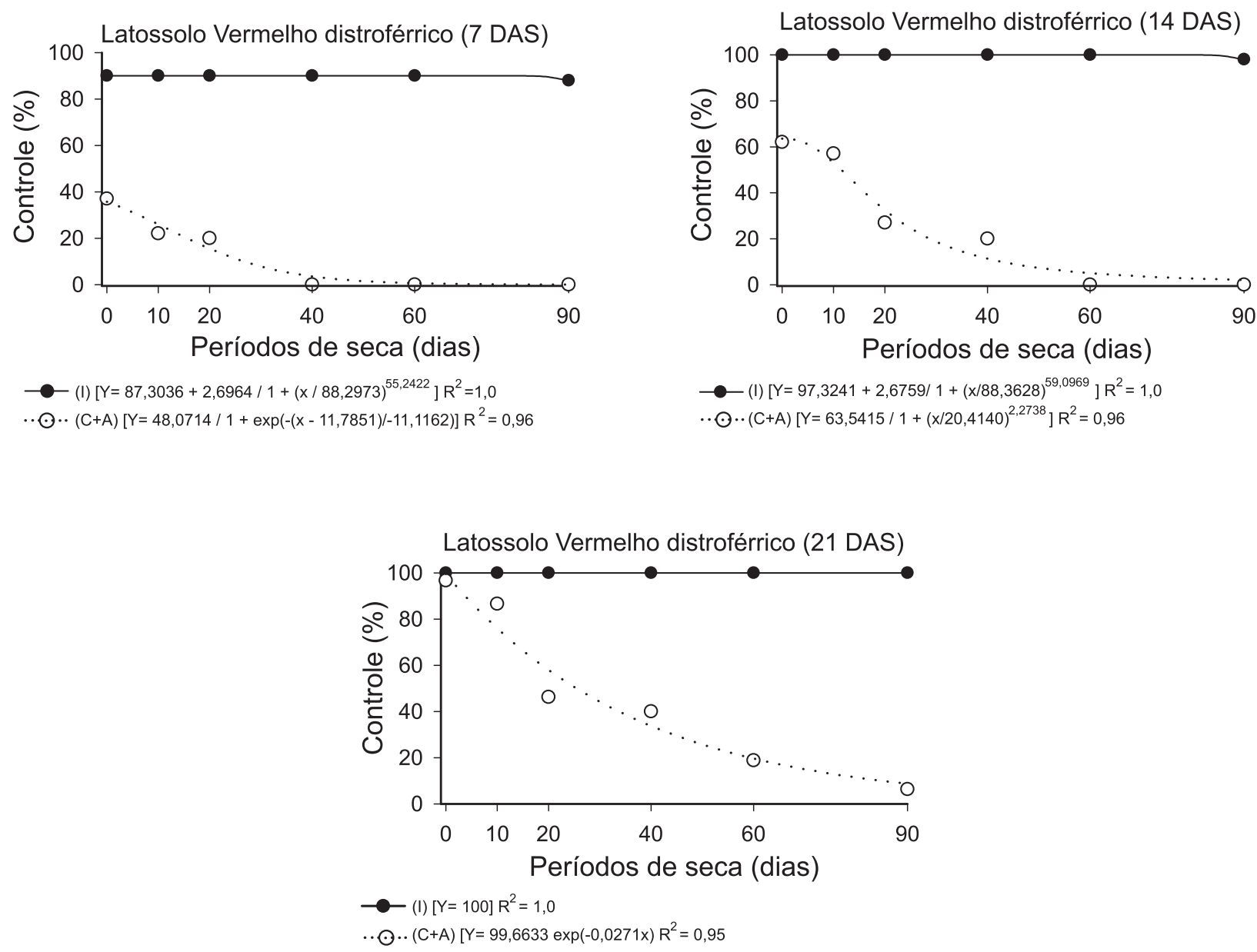

Figura 2 - Efeito residual dos herbicidas isoxaflutole (I) e clomazone (C) + ametryn (A) sobre S. bicolor aos 7, 14 e 21 DAS, aplicados em Latossolo Vermelho distroférrico.

seca; C. sativus semeado após 90 dias de seca foi controlado em 70 e $51,3 \%$, respectivamente (Figura 3). Em campo, estudos indicam que a persistência biológica do imazapyr é dependente, sobretudo, da dose e dos fatores ambientais, com degradação mais rápida em clima quente e úmido (Firmino, 2001).

Vivian et al. (2007a) afirmam que para os herbicidas tryfloxysulfuron-sodium e ametryn a adsorção foi maior em Latossolo Vermelho distroférrico, com alto teor de matéria orgânica e argila, mas que outros fatores podem influenciar as características adsortivas desse solo, como o tipo e a quantidade de argilominerais. Segundo ainda Vivian et al. (2007b), nas avaliações de persistência e lixiviação de ametryn e trifloxysulfuron-sodium em áreas de canade-açúcar, a persistência do primeiro foi de 180 dias após aplicação na superfície do solo, embora não tenham sido detectados resíduos de trifloxysulfuron-sodium após 18 dias da aplicação em pós-emergência.

$\mathrm{O}$ isoxaflutole proporcionou controle de S. bicolor de $100 \%$ em todos os períodos em que o solo foi mantido no seco, em avaliação realizada aos 21 DAS (Figura 4). O resultado obtido assemelha-se aos dados de trabalhos instalados em campo, em que se observa controle acima de $80 \%$ para este herbicida por períodos de até 80 dias de seca para espécies como Brachiaria decumbens, B. plantaginea, Digitaria horizontalis, Portulaca oleracea, Cenchrus echinatus, Galinsoga parviflora, Amaranthus viridis e Ageratum conyzoides (Marchiori Jr. et al., 2005; Costa \& Rozanski, 2003; Adoryan et al., 2002; Montório et al., 2002). Oliveira et al. (2006) verificaram que, à medida que aumenta o tempo e o número de irrigações entre a aplicação do herbicida 

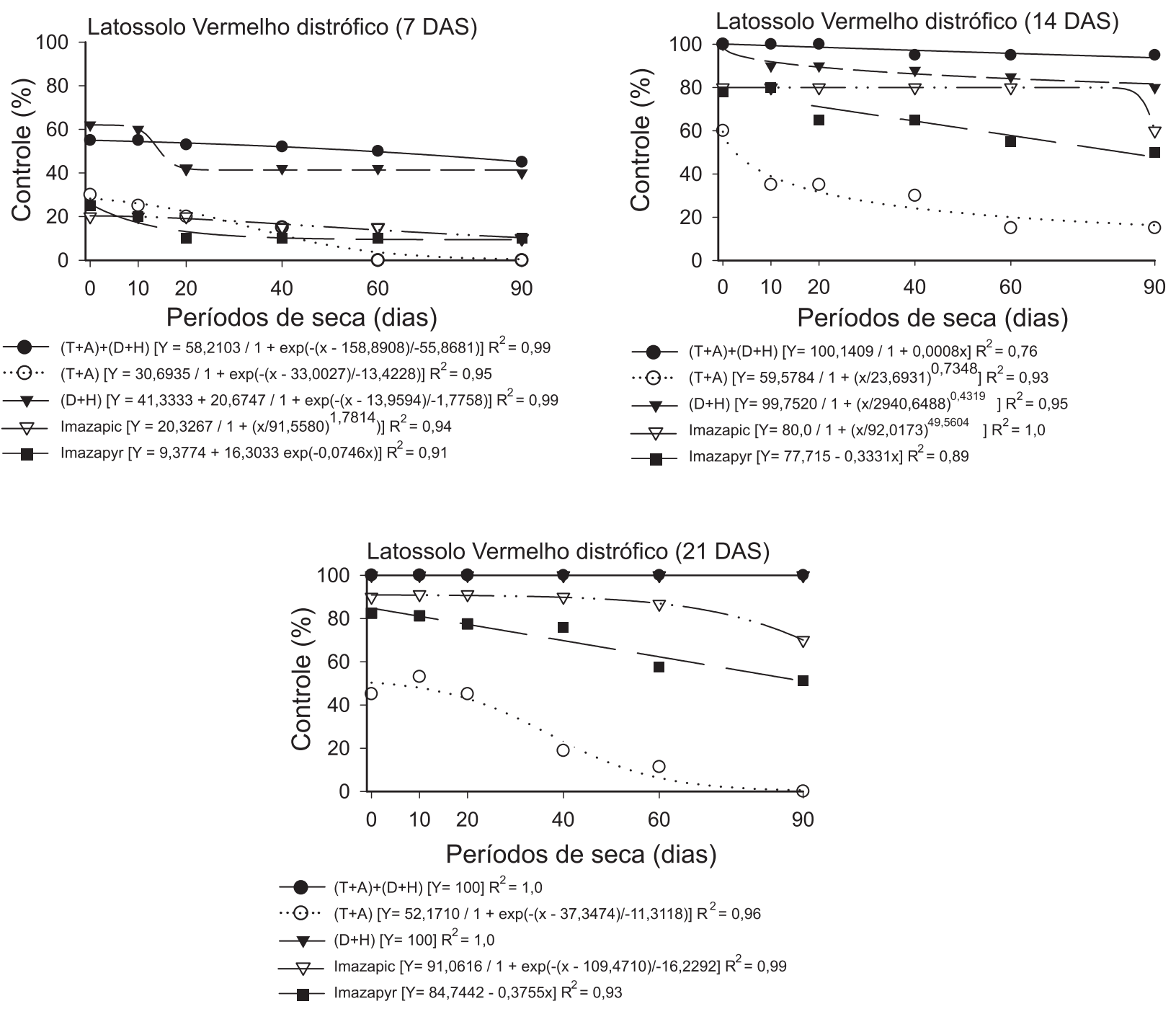

Figura 3 - Efeito residual dos herbicidas trifloxysulfuron-sodium $(\mathrm{T})+\operatorname{ametryn}(\mathrm{A})+$ diuron $(\mathrm{D})+$ hexazinone $(\mathrm{H})$, trifloxysulfuronsodium + ametryn, diuron + hexazinone, imazapic e imazapyr sobre C. sativus aos 7, 14 e 21 DAS, aplicados em Latossolo Vermelho distrófico.

e a semeadura de uma espécie bioindicadora, há redução no potencial de controle exercido pelo isoxaflutole em condições de Latossolo Vermelho distrófico.

A mistura formulada clomazone + ametryn apresentou aos 7 e 14 DAS baixa capacidade de controle da espécie biondicadora $(<60 \%)$. Aos 21 DAS, observou-se que essa mistura afetou S. bicolor em mais de $80 \%$ quando submetido o solo a um período de até dez dias de seca depois da aplicação; após este período, detectou-se redução na atividade herbicida à medida que se aumentou o período de seca (Figura 4).
Herbicidas aplicados à superficie do solo são freqüentemente perdidos, especialmente se ocorrer um período prolongado de seca após a aplicação (Silva et al., 2007). É possivel que ocorram perdas em função do processo de fotodegradação, além de outros fatores que podem estar envolvidos, como a volatilização, acentuada pela temperatura elevada na superficie do solo, a degradação química e biológica e a sorção, que devem ser considerados para explicar o desaparecimento dos herbicidas no solo (Silva et al., 2007).

Os resultados deste trabalho permitiram concluir que, mesmo na aplicação de herbicidas 

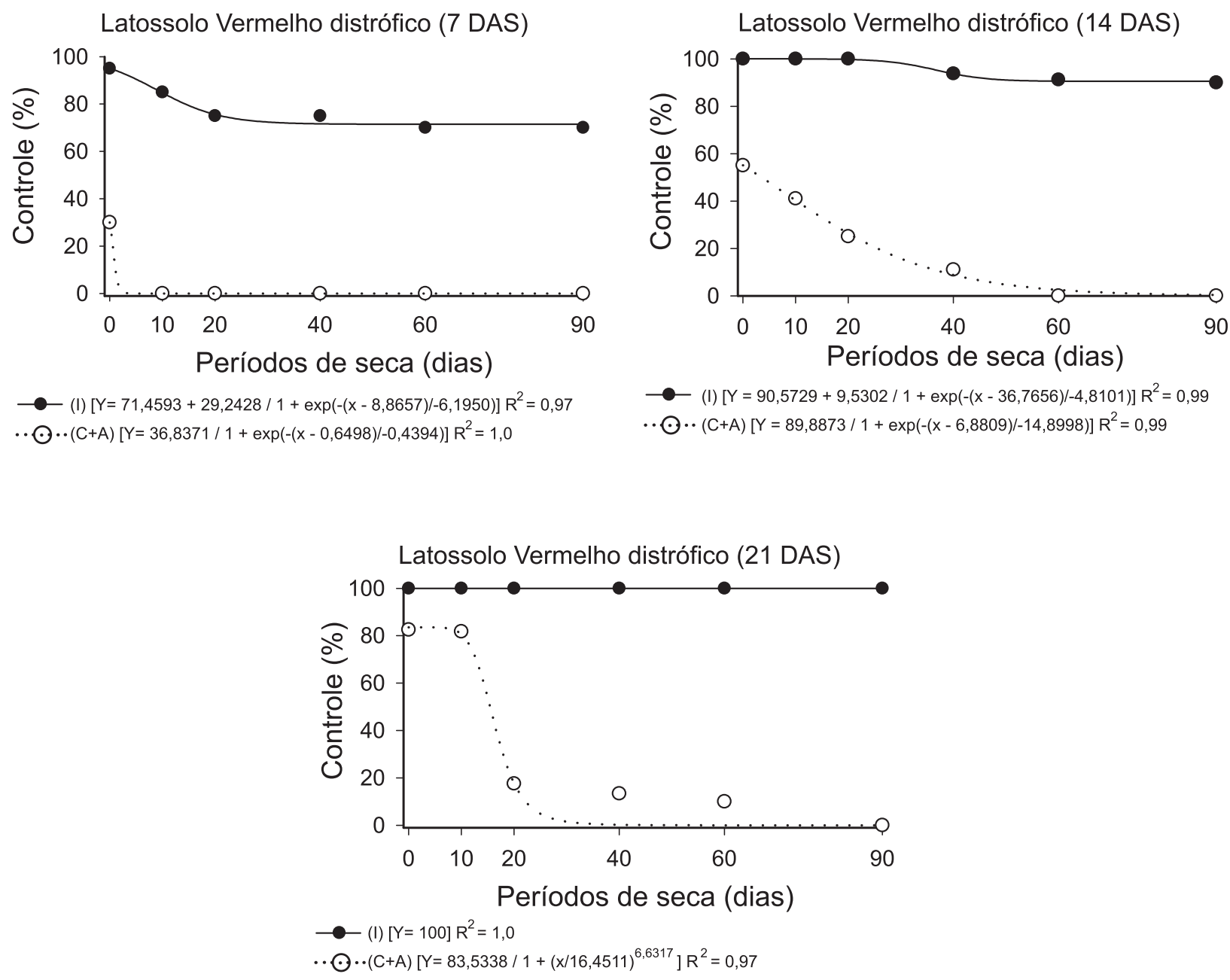

Figura 4 - Efeito residual dos herbicidas isoxaflutole (I) e clomazone (C) + ametryn (A) sobre S. bicolor aos 7, 14 e 21 DAS, aplicados em Latossolo Vermelho distrófico.

após períodos de seca, houve maior efeito residual no solo com maior teor de argila e matéria orgânica. A mistura clomazone + ametryn apresentou a menor estabilidade ao longo das avaliações em ambos os solos, não sendo recomendada para aplicação em períodos secos. Os herbicidas imazapic e imazapyr tiveram seus efeitos tóxicos diminuídos, em ambos os solos, quando submetidos a um período de seca maior que 60 dias. Diuron + hexazinone isolado e em mistura com trifloxysulfuron-sodium + ametryn e o isoxaflutole controlaram totalmente os bioindicadores mesmo com 90 dias de seca após aplicação em ambos os solos.

\section{LITERATURA CITADA}

ADORYAN, M. L.; BENDECK, O. B.; GELMINI, G. A. Avaliação do herbicida isoxaflutole na cultura de Pinus caribae. In: CONGRESSO BRASILEIRO DA CIÊNCIA DAS PLANTAS DANINHAS, 23., 2002, Gramado.

Resumos... Londrina: SBCPD/Embrapa Clima Temperado, 2002. p. 577

ANDERSON, W. P. Weed science principles. New York: West Publishing, 1983. $655 \mathrm{p}$

ASOCIACION LATINOAMERICANA DE MALEZAS ALAM. Recomendaciones sobre unificación de evaluación en ensayos de control de malezas. ALAM, v. 1, n. 1, p. 35-38, 1974. 
AZÂNIA, C. A. M. et al. Seletividade de herbicidas. III Aplicação de herbicidas em pós emergência inicial e tardia da cana-de-açúcar na época da estiagem. Planta Daninha, v. 24, n. 3 , p. 489-495, 2006.

BOUCHARD, D. C.; ENFIELD, C. G.; PIWONI, M. D. Transport processes involving organic chemicals. In: SAWHNEY, B. L. (Ed.). Reactions and movement of organic chemicals in soils. Madison, Soil Science Society of America, 1989. p. 349-372

COSTA, E. A. D.; ROZANSKI, A. Eficácia da aplicação de isoxaflutole associado com ametryn ou diuron no controle de plantas daninhas em cana-de-açúcar. B. Inf. SBCPD, v. 9, n. 1, p. 14-21, 2003.

EMPRESA BRASILEIRA DE PESQUISA AGROPECUÁRIA - EMBRAPA. Sistema brasileiro de classificação de solos. Brasília: 1999. 412 p

FIRMINO, L. E. Sorção e movimento do imazapyr em três solos. 2001. 72 f. Dissertação (Mestrado em Fitotecnia) - Universidade Federal de Viçosa, Viçosa, MG, 2001.

FREITAS, S. P. et al. Controle químico de Rottboelia exaltata em cana-de-açúcar. Planta Daninha, v. 22, n. 3, p. 461-466, 2004.

GUIMARÃES, G. L. Impactos ecológicos do uso de herbicidas ao meio ambiente. Série Técnica IPEF, v. 4, p. $159-180,1987$

LANGENBACH, T; CORREIA, F. V. Dinâmica da distribuição e degradação de atrazina em Argissolo VermelhoAmarelo sob condições de clima tropical úmido. R. Bras. Ci. Solo, v. 30, n. 1, p. 1-10, 2006

MARCHIORI JR., O. et al. Efeito residual de isoxaflutole após diferentes períodos de seca. Planta Daninha, v. 23, n. 3 , p. $491-499,2005$

MILLER, L. C.; RESENDE, L. C. L.; MEDEIROS, A. M. L. Manejo de herbicidas na lavoura de cana-de-açúcar. STAB, v. 13, p. 9-13, 1995.

MITRA, S.; BHOWMILK, P. C.; XING, B. Sorption and desorption of the diketonitrile metabolite of isoxaflutole in soils. Environ. Poll., v. 108, n. 2, p. 183-190, 2000.
MONTÓRIO, G. A. et al. Avaliação da eficiência agronômica de herbicidas aplicados em área de alta infestação de capim colchão (Digitaria horizontalis Willd) na cultura de cana-deaçúcar. In: CONGRESSO BRASILEIRO DA CIÊNCIA DAS PLANTAS DANINHAS, 23., 2002, Gramado. Resumos... Londrina: SBCPD/Embrapa Clima Temperado, 2002. p. 508.

OLIVEIRA JR., R. S. et al. Influence of drought periods on the residual activity of isoxaflutole in soil. Planta Daninha, v. 24, n. 4, p. 733-740, 2006.

PROCÓPIO, S. O.; SILVA, A. A.; VARGAS, L. Manejo e controle de plantas daninhas em cana-de-açúcar. In: VARGAS, L.; ROMAN, E. S. (Eds.) Manual de manejo e controle de plantas daninhas. Bento Gonçalves: Embrapa Uva e Vinho, 2004. p. 397-452.

RENNER, K. A. et al. Effect of tillage an application method on corn (Zea mays) response to imidazolinone residues in soil. Weed Technol., v. 12, n. 2, p. 281-285, 1998.

RODRIGUES, B. N.; ALMEIDA, F. S. Guia de herbicidas. Londrina: IAPAR, 2005. 592 p.

SILVA, A. A. et al. Controle de plantas daninhas. Brasília: Associação Brasileira de Educação Agrícola Superior; Viçosa, MG: Universidade Federal de Viçosa, 1999. 260 p.

SILVA, A. A. et al. Herbicidas: classificação e mecanismo de ação. In: SILVA, A. A; SILVA, J. F. (Eds.). Tópicos em manejo de plantas daninhas. Viçosa, MG: Universidade Federal de Viçosa, 2007. p. 83-147.

SOUZA, G. V. R. et al. Exsudato radicular de imazapyr aplicado sobre mudas de diferentes clones de eucalipto. Planta Daninha, v. 24, n. 1, p. 141-147, 2006.

VELINI, E. D. et al. Dinâmica de tebuthiuron em palhadas de cana-de-açúcar. Efeito de lâminas de chuva, surfactantes e volumes simulados de aplicação. In: CONGRESSO BRASILEIRO DA CIÊNCIA DAS PLANTAS DANINHAS, 23., 2002, Gramado. Resumos... Londrina: SBCPD/Embrapa Clima Temperado, 2002. p. 705.

VIVIAN, R. et al. Adsorção e dessorção de trifloxysulfuronsodium e ametryn em solos brasileiros. Planta Daninha, v. 25, n. 1 , p. $97-109,2007$ a.

VIVIAN, R. et al. Persistência e lixiviação de ametryn e trifloxysulfuron-sodium em solo cultivado com cana-deaçúcar. Planta Daninha, v. 25, n. 1, p. 111-124, 2007 b. 